\title{
MENAKAR IDEOLOGI REPUBLIK ISLAM IRAN: KONTESTASI ANTARA IDEOLOGI DAN PRAGMATISME DALAM POLITIK
}

\author{
A. Kemal Riza \\ Universitas Islam Negeri Sunan Ampel Surabaya I II. A. Yani I I 7 Surabaya \\ kemalespe@yahoo.com
}

Abstract: Iran declared as an Islamic state since its 1979 Islamic revolution. Since leadership of Ayatullah Khomeini, Islamic ideology has been carried out in all levels of the state. In politics, it was conducted by creating wilayah al-faqih, in which the ulama plays important and decisive role. Iran even tried to expand this ideology outside its border, especially in areas with considerable number of Shi'i population. However, in its practice, the implementation of this Islamic ideology should also accommodate pragmatism and other aspects that contradict that ideology, namely nationalism and cultural pluralism. In politics, this is reflected by the emergence of ideologists and reformists-pragmatists. This dichotomy can be witnessed in presidential elections. While Ali Khamenei and Mahmoud Ahmadinejad are considered ideologists, Ali Akbar Rafsanjani, Muhammad Khatami and Hassan Rouhani are reformists-pragmatists. Ideological expansion which was proven backfired was also put on halt. In social-cultural expression of the society, there is growing trend to identify Iran using pre-Islamic symbols. This is happen mostly among younger generation who do not take part in the 1979 revolution.

Keyword: Iran, wilâyah al-faqłh, pragmatism

Abstrak: Iran adalah sebuah negara yang mengumumkan sebagai Negara Islam modern sejak revolusi Islam di tahun 1979. Di bawah kepemimpinan Ayatullah Khomeini, ideologi Islam dilaksanakan dalam berbagai cara dan mekanisme, antara lain kepemimpinan ulama (wilâyah al-faqîh) yang tercermin dalam peran sentral ulama dalam politik kenegaraan dan implementasi besar-besaran nilai-nilai keislaman dalam politik dan kehidupan sosial. Iran bahkan berusaha melakukan ekspansi ideologi Islam mereka ke wilayah-wilayah Islam lainnya, khususnya yang memiliki paham Syi'ah yang sama. Akan tetapi, dalam praktiknya upaya ini tidak dapat dilaksanakan secara murni tanpa 
akomodasi terhadap pragmatisme politik. Dalam politik kenegaraan, hal ini tercermin dengan kemunculan kelompok ideologis dan pragmatis-reformis dalam politik, diantaranya dalam pemilihan presiden. Beberapa presiden Iran tergolong ideologis seperti Ali Khamenei dan Mahmoud Ahmadinejad, sedangkan Ali Akbar Rafsanjani, Muhammad Khatami dan presiden saat ini Hassan Rouhani termasuk reformis-pragmatis. Ekspansi ideologis yang tidak menghasilkan apa-apa kecuali resistensi juga nampak dibatasi. Dalam kehidupan sosial, semakin banyak kecenderungan masyarakat Iran untuk menonjolkan identitas Persia pra-Islam, khususnya di kalangan generasi muda yang tidak berpartisipasi dalam revolusi Iran di tahun 1979.

Kata Kunci: Iran, wilâyah al-faqðh, pragmatisme

\section{Pendahuluan}

Dalam Islam, kelompok Syi'ah Imamiyah memiliki konsep politik yang relatif mapan. Hal ini terwujud dalam diri imam yang tidak hanya memiliki otoritas di bidang keagamaan tetapi juga bidang politik. Dalam politik, Syi'ah memperjuangkan ideologi Islam, yaitu terlaksananya syariat Islam dalam kehidupan privat ataupun publik masyarakat yang harus diwujudkan dalam sebuah pemerintahan Islam. Mereka mempercayai hal ini harus diterapkan tidak hanya pada saat para imam masih hidup, tetapi juga setelah mereka tidak bersama komunitas Syi'ah. Sepeninggal imam, para ulama sebagai pengganti imam (nâib khash) meneruskan peran imam, khususnya di bidang keagamaan. Konsep ini disebut wilâyah al-faqûh. Konsep ini diperluas oleh Ayatullah Khomeini dengan memberikan landasan ideologis bagi kewenangan ulama di bidang politik.

Dengan berhasilnya revolusi Islam di Iran di tahun 1979, konsep wilâyah al-faqth ini lantas diterapkan dalam Republik Islam Iran. Konsep ini dituangkan dalam konstitusi Iran dimana ulama memegang jabatan-jabatan penting yang luas dan menentukan dalam politik Iran. Dalam praktiknya, kekuasaan ulama dalam politik berpengaruh pada segala aspek kenegaraan, mulai dari urusan keamanan negara dan militer, politik luar negeri, bahkan 
ekonomi. Akan tetapi, perkembangan dua puluh tahun terakhir, khususnya sepeninggal Khomeini di tahun 1989, menunjukkan banyaknya kritik dan bahkan penentangan yang dalam jangka panjang dapat menjadi ancaman serius bagi kekuasaan politik ulama dan bahkan ideologi politik Islam Syi'ah. Kritik-kritik tersebut disebabkan oleh keputusan-keputusan yang bertentangan dengan aspirasi masyarakat dan karena terlalu luasnya peran ulama dalam politik.

Sejumlah masyarakat Iran juga telah mulai menggunakan konsep-konsep yang tidak selalu berbasis Islam, khususnya nasionalisme dan identitas Persia, sebagai bentuk resistensi terhadap ideologi negara. Selain itu, dalam praktiknya, politik tidak selalu sejalan dengan nilai-nilai agama karena pertimbangan pragmatis juga nampak selain pertimbangan ideologis. Persepsi masyarakat Iran pun mulai luntur terhadap peran ulama ini dan ideologi Islam secara keseluruhan. Kondisi-kondisi ini menggerus relevansi imâmah versi wilâyah al-faqth sebagai ideologi politik di Iran.

\section{Genealogi dan Legitimasi Otoritas Ulama Syi'ah}

Setelah wafatnya Rasulullah SAW pada abad pertama hijriyah, otoritas keagamaan dalam Islam dibedakan menjadi dua, yaitu kekuasaan politik dan otoritas menafsirkan agama. Yang pertama memunculkan kekhalifahan sedangkan yang kedua ini ditandai dengan kemunculan gerakan kajian hadis dan kemunculan madzhab fikih. Ulama memegang otoritas kedua ini berdasarkan karena kepakaran mereka dalam sumber-sumber ilmu keagamaan, khususnya al-Qur'an dan hadis Nabi. Dengan demikian, para ulama adalah pewaris Nabi dan pandanganpandangan keagamaan mereka seharusnya didengar.

Dalam tradisi Sunni, terdapat ungkapan yang membedakan antara kekuasaan agama (dîn) dengan kekuasaan temporal (politik). Dalam praktiknya, kekuasaan politik dilaksanakan oleh Khalifah ataupun Sultan, sedangkan kekuasaan agama ini dijalankan secara bersama dan kolektif di antara para ulama. 
Mereka tidak memiliki institusi tersendiri, meskipun ulama bisa memiliki otoritas keagamaan yang sangat kuat melalui institusi ijma'.

Konsep pemisahan kekuasaan di atas terjadi dalam tradisi Sunni dan Syi'ah di abad awal Islam. Akan tetapi, konsep tentang otoritas dalam tradisi Syi'ah berkembang secara bertolak belakang di masa-masa sesudahnya. Syi'ah menolak legitimasi kekhalifahan yang ada dan menganggap Ali bin Abi Talib dan keturunannya sebagai penerus Nabi secara utuh, baik sebagai khalifah di bidang politik dan sebagai pemimpin agama (imâm) yang terus menerima wahyu dan terjaga dari dosa (ma'shîm). ${ }^{1}$ Menurut tradisi Syi'ah, imam inilah yang dimaksud dalam Surat al-Nisa ayat $59 .{ }^{2}$

Sejak abad ke-8 Masehi dan seterusnya, kepemimpinan imam yang kharismatik sebagai pemimpin politik tertinggi sekaligus sebagai guru di bidang keagamaan dikaitkan secara erat dengan kualitas keilmuan yang dimiliki oleh sang imam. ${ }^{3}$ Hal ini terbukti penting di masa setelah ghaybah al-imâm (occultation, hilangnya imam), ketika otoritas keilmuan sang imam lantas ditransfer kepada para ulama, kecuali aspek 'ishmah (terjaga dari dosa). Dalam perkembangannya, otoritas ulama Syi'ah memiliki dua ciri khas. Otoritas tersebut adalah sebuah bentuk otoritas imam yang merupakan penerus kenabian dan bahwa otoritas tersebut berbasis keilmuan. ${ }^{4}$ Otoritas keilmuan ini diperoleh dari kepakaran mereka sebagai ahli fikih (jurist) yang berfungsi menafsirkan syari'at.

Pada awalnya, peran ini dilakukan ulama Syi'ah dengan hanya mengandalkan pemahaman terhadap teks-teks suci (al-

\footnotetext{
I Said Amir Arjomand, "Introduction: Shiism, Authority and Political Culture", dalam Said Amir Arjomand (ed), Authority and Political Culture in Shi'ism, (New York: SUNY Press, 1988), I-3.

2 Terjemahnya: "Hai orang-orang yang beriman, taatilah Allah dan taatilah Rasul (Nya), dan Ulil Amri di antara kamu. Kemudian jika kamu berlainan pendapat tentang sesuatu, maka kembalikanlah ia kepada Allah (Al-Qur'an) dan Rasul (sunnahnya), jika kamu benar-benar beriman kepada Allah dan hari kemudian. Yang demikian itu lebih utama (bagimu) dan lebih baik akibatnya".

${ }^{3}$ Etan Kohlberg, "Imam and Community in the Pre-Ghayba Period", dalam Said Amir Arjomand (ed), Authority and Political Culture in Shilism, (New York: SUNY Press, 1988), 27.

${ }^{4}$ Said Amir Arjomand, "Introduction: Shiism, Authority and Political Culture"..., 4.
} 
Qur'an dan Hadis). Akan tetapi, ketika berbagai permasalahan hukum mengharuskan penggunaan ijtihâd, maka mereka memperkenalkan ushûl figh. ${ }^{5}$ Terakhir, Allamah al-Hilli merumuskan secara lebih tuntas konsep ini dengan menepis ketidakmungkinan memperoleh hukum yang qath' $i$, apalagi setelah periode ghaybah. ${ }^{6}$ Al-Bihbihâni menegaskan posisi kuat ijtihad dalam tradisi Syi'ah dua belas imam setelah kelompok Ushûli dan Akhbari di abad ke-17-18.7 Penerimaan ijtihad dalam tradisi Syi'ah ini menjadi langkah penting dalam perkembangan otoritas ulama fikih di kalangan ulama Syi'ah. ${ }^{8}$ Kemudian muncullah ulama mujtahid dalam tradisi Syi'ah.

Kemunculan mujtahid ini menjadikan ulama yang masuk kategori ini sebuah golongan ulama tersendiri dalam tradisi Syi'ah. ${ }^{9}$ Kemunculan mujtahid pada akhirnya memunculkan kalangan awam yang harus menerima pandangan ulama dalam masalah keagamaan (taqlid). Dikotomi ini kemudian turut memperkuat otoritas mujtahid atas orang awam dalam tradisi Syi'ah dua belas Imam dan juga menempatkan doktrin ijtihad visà-vis taqlíd sebagai inti bangunan hukum Syi'ah yang kemudian menjadi dasar berdirinya lembaga marja' al-taqlîd. ${ }^{10}$ Hal ini berlanjut dengan pengakuan keunggulan beberapa mujtahid

\footnotetext{
${ }^{5}$ Moojan Momen, An Introduction to Shi'l Islam: The History and Doctrine of Twelve Shi' ism, (New Haven: Yale University Press, 1985)

${ }^{6}$ Menurut Moojan Momen, di antara rumusannya adalah dalam situasi dimana beberapa ulama berbeda pandangan. Hal ini menimbulkan kesulitan karena salah satu pandangan tersebut pasti ada yang salah. Al-Hilli menyatakan bahwa bisa saja dua pendapat yang berbeda tersebut benar. Jika tidak benar, maka sang Imam tersembunyi akan muncul dan mengoreksi pendapat yang tidak benar tersebut. Ibid., 187.

${ }^{7}$ Ibid., 186.

8 Penerimaan terhadap 'aql ini didasarkan pada argumen bahwa meskipun Tuhan adalah sumber hukum yang utama, Dialah yang menciptakan akal untuk menemukan hukum. Otoritas syari'ah diperoleh dari kesesuaiannya dengan akal. Sehingga, keputusan hukum yang sesuai dengan akal, sebagaimana yang diperoleh melalui proses ijtihad, dapat dipastikan secara hukum valid. Meskipun pada akhirnya putusan tersebut berseberangan dengan putusan mujtahid lainnya. Ibid., |87-I88.

${ }^{9}$ lbid., 186.

${ }^{10}$ Said Amir Arjomand, "Introduction: Shiism, Authority and Political Culture" ..., 6.
} 
senior dalam menetapkan hukum dan menjadikannya putusan akhir yang mengikat. ${ }^{11}$

Menguatnya posisi ulama-mujtahid ini berlanjut dan mulai menampakkan dimensi politisnya pada era Kerajaan Safawi (15011722 M), kerajaan besar pertama dimana paham Syi'ah dua belas Imam menjadi agama resmi negara dan semakin kokoh di masa kerajaan Qajar. Dalam prosesnya, peran ulama-mujtahid Syi'ah dengan al-Karaki (w. 1534 M) sebagai figur utamanya menggantikan Sadr, yaitu jabatan keagamaan dalam kerajaan Safawi. ${ }^{12}$ Kemudian, Shaykh Murtadha Ansâri (1799-1864 M) mengembangkan teori hukum Syi'ah secara lebih luas sehingga memberi kewenangan para mujtahid Syi'ah berijtihad dalam bidang-bidang yang dimungkinkan direstui oleh Imam. Dengan demikian, para mujtahid Syi'ah dapat melakukan ijtihad hampir di semua bidang. Hal ini juga yang memunculkan doktrin wilâyah alfaqih, yaitu ide tentang mandat bagi ulama fikih sebagai wakil imam dalam semua aspek otoritasnya sebagai nâib âm. ${ }^{13}$

\section{Evolusi Konsep Wilâyah al-Faqîh}

Berdirinya Rezim Pahlevi yang sekuler dengan melakukan kudeta terhadap Dinasti Qajar di awal abad ke-20 merubah dominasi dan peran besar ulama ini. Rezim Pahlevi mengambil alih peran kehakiman yang secara tradisional dikelola masyarakat ulama. Terbukanya Rezim Pahlevi terhadap pengaruh luar, khususnya Barat, membuat Iran terbuka terhadap pengaruh paham-paham baru. Sebagian masyarakat Iran menjadi nasionalis, sekuler, Marxist, modern sampai dengan radikal. Rezim Pahlevi juga melahirkan masyarakat kelas elit menengah yang berpendidikan modern. Hal ini jelas berbeda dengan masyarakat ideal yang diidealkan komunitas ulama. Di sisi lain, rezim ini juga melakukan perombakan sistem pemerintahan agar menjadi negara

\footnotetext{
" Hamad Kazemi Mussavi, "Usuliyya", dalam Richard C. Martin (ed), Encyclopedia of Islam and the Muslim World, (New York: McMillan Reference USA, 2004), 718.

12 Said Amir Arjomand, "Introduction: Shiism, Authority and Political Culture"..., 6.

${ }^{13}$ Hamad Kazemi Mussavi, "Usuliyya"..., 7 I8.
} 
yang modern. Pada titik ini, Rezim Pahlevi juga mereformasi sistem peradilan yang mengharuskannya mengambil alih peranperan yang selama ini menjadi kewenangan ulama, seperti kekuasaan kehakiman dan beberapa lembaga pendidikan. Hal ini tentu menimbulkan keresahan dari kelompok ulama.

Sebagai reaksinya, ulama Syi'ah kemudian mengembangkan doktrin pemerintahan Islam yang digalinya dari berbagai sumber, termasuk diskursus yang dikembangkan oleh kalangan Sunni seperti al-Mawdudi dan Sayyid Qutb. Mereka menggunakan konsep wilâyah al-faq'h yang semula dimaknai secara sempit menjadi sebuah doktrin untuk memberikan justifikasi kekuasaan ulama dalam aspek politik. Perluasan doktrin sehingga mencakup kewenangan politik ini mengindikasikan penentangan ulama terhadap rezim yang berkuasa. Tokoh-tokoh penting di balik gerakan ulama ini adalah Ayatullâh Khomeini dan pendukungnya seperti Murtazha Muthahhari dan Husayn Ali Montaziri. ${ }^{14}$ Secara khusus, Khomeini-lah yang mengampanyekan perluasan doktrin wilâyah al-faq ĥt melalui pidato-pidatonya. ${ }^{15}$

Secara singkat, wilâyah al-faquh adalah kekuasaan ulama dalam hal-hal yang sebenarnya menjadi kewenangan Imam sebagaimana dijelaskan sebelumnya. Dalam sejarahnya, peran ini dijalankan oleh para ulama secara terbatas dalam aspek-aspek keagamaan seperti shalat Jum'at dan pembagian zakat. Akan tetapi, dalam pandangan Khomeini wilâyah al-faqîh diperluas dalam bidang hukum-hukum publik juga. Memberikan kekuasaan kepada ulama atau faqih lebih baik karena ulama selalu berlandaskan hukum Islam. Sedangkan hukum Islam adalah lebih unggul daripada hukum sekuler manapun. Seorang faqih dituntut untuk menerapkan hukum Islam dan oleh karenanya berkewajiban memperoleh kekuasaan politik agar dapat mendirikan

\footnotetext{
${ }^{14}$ Abbas Amanat, "From ljtihad To Wilayat-i Faqih: The Evolving of the Shili Legal Authority into Political Power", dalam Abbas Amanat (ed), Apocaliptic Islam and Iranian Shi'ism, (New York: IB Tauris, 2009), 181.

${ }^{14}$ Moojan Momen, An Introduction to Shi'l Islam:..., 186.

15 lbid., I87- 190.
} 
pemerintahan Islam yang akan menerapkan hukum Islam. ${ }^{16}$ Pandangan revolusioner Khomeini ini tidak hanya bertujuan untuk menentang Rezim Pahlevi, tetapi juga untuk menyatukan masyarakat ulama. Dengan dukungan beberapa aktor lain, revolusi ulama ini berhasil menggulingkan Rezim Pahlevi di tahun 1979 dan berdirilah negara Islam Iran dengan otoritas politik tertinggi di tangan ulama.

\section{Ideologi Islam dalam Konstitusi Iran}

Dalam pembukaan konstitusi Republik Islam Iran disebutkan bahwa konstitusi ini adalah deklarasi dasar sosial, budaya, politik dan ekonomi dari masyarakat Iran yang berbasis pada prinsipprinsip dan norma-norma Islam yang mencerminkan keinginan hati masyarakat Islam. ${ }^{17}$ Konstitusi ini mengklaim bahwa pemerintahan Islam inilah yang menjadi tujuan akhir umat Islam. ${ }^{18}$ Menurut konstitusi, umat Islam tidak terbatas pada wilayah Iran semata sehingga berhasilnya perjuangan Islam di Iran harus dikembangkan tidak hanya di dalam Iran tetapi juga dikembangkan di luar Iran. Konstitusi Iran juga menekankan perjuangannya melawan musuh-musuh Iran, khususnya Amerika Serikat. ${ }^{19}$

Secara eksplisit, pembukaan Konstitusi Iran juga menyebutkan peran Ayatullah Uzmâ Imam Khomeini sebagai marja' al-taqlíd yang telah berperan besar dan menentukan keberhasilan revolusi ini. ${ }^{20}$ Dalam Konstitusi Iran ini, pemerintahan Islam yang diterapkan berbasis pemerintahan oleh ulama fikih (velâyat-e al-faqîh) sebagai wakil dari imam yang ghâib

\footnotetext{
16 bid., 191.

17 "Iran (Islamic Republic of)'s Constitution of 1979 with Amendments through 1989", dalam https://www.constituteproject.org/constitution//ran_1989.pdf?lang=en, diakses pada 10 Mei 2017, 3.

$18 \mathrm{lbid}$.

19 James S. Ribbon, "Iranian Ideology After The Nuclear Deal", Iran Strategy Brief, The American Foreign Policy Council, 8, Januari 2017, 2.

${ }^{20}$ Constituteproject.org, Iran (Islamic Republic of)'s Constitution of 1979 with Amendments through 1989, Pasal I dan 107
} 
sebagaimana dikampanyekan dalam perjuangan Khomeini. ${ }^{21}$ Lebih lanjut, konstitusi ini menjelaskan bahwa velâyat-e al-faqîh bersumber dari limpahan kewenangan Tuhan dan kepemimpinan imam. Seorang faqth yang memenuhi syarat akan ditunjuk sebagai pimpinan wilâyah al-faqîh ini. Dia bertugas untuk memastikan seluruh lembaga negara agar tidak melenceng dari tanggung jawab keislaman mereka. ${ }^{22}$ Klausul terakhir inilah yang memberikan kekuasaan yang besar terhadap ulama dalam pemerintahan Republik Islam Iran. Kekuasaan tersebut antara lain kekuasaan pengawasan dalam menunjuk pimpinan kehakiman, militer, intelejen negara dan media penyiaran. Dia juga memiliki pengaruh untuk mengendalikan segmen ekonomi tertentu. ${ }^{23}$

Dalam struktur kekuasaan Republik Islam Iran, pemimpin tertinggi atau pemimpin revolusi harus dijabat oleh ulama senior (Ayatullah). Berdasarkan Konstitusi Iran, pemimpin tertinggi adalah panglima tertinggi militer dan menguasai Dewan Keamanan Nasional Tinggi. Dia bisa memberhentikan presiden jika diusulkan oleh Parlemen dan Mahkamah Agung. Dia berhak menunjuk separuh anggota Dewan Pelindung dan menunjuk kepala Mahkamah Agung. Sebagaimana disebutkan dalam konstitusi, pemimpin tertinggi dijabat oleh Khomeini, dan sepeninggalnya di tahun 1989, jabatan ini diteruskan oleh Ali Khamenei setelah dipilih oleh Dewan Ahli.

Dewan Pelindung bertugas untuk memastikan perundangan sejalan dengan hukum Islam. Perannya yang lain adalah menyeleksi calon yang dipilih dalam pemilihan dan mengesahkan hasil pemilihan. Presiden dipilih oleh rakyat, tetapi tetap berada di bawah kekuasaan pemimpin tertinggi sehingga kekuasaannya terbatas. Kekuasaannya di bidang keamanan negara dan isu-isu strategis juga dibatasi oleh Korps Garda Revolusi Iran.

\footnotetext{
${ }^{21}$ Ibid., Pasal 5.

$22 \mathrm{lbid}$.

${ }^{23}$ Ali Banuazizi, Islamic State and Civil Society in Iran, Invited Joseph Sterlitz Annual Lecture in Middle Eastern Studies, Tel Aviv University, I 8 April, 1999, 3.
} 
Presiden berhak menunjuk anggota kabinet, menyusun anggaran negara dan bertugas memungut pajak. Majelis (Parlemen) juga dipilih dalam pemilihan. Tugasnya menyetujui usulan anggota kabinet dan anggaran negara, serta menyusun perundangan. Lembaga Tinggi lainnya adalah Dewan Ahli yang secara formal memiliki tugas mengawasi pimpinan tertinggi dan melakukan amandemen Konstitusi jika diperlukan. ${ }^{24}$ Dalam praktiknya, penentuan jabatan dan kontestasi perebutan posisiposisi politik senantiasa mempertemukan dua kelompok besar di kalangan ulama, yaitu kelompok konservatif-ideologis seperti Ayatullah Ali Khamenei (Presiden Iran 1981-1989) dan Mahmoud Ahmadinejad, Presiden Iran 2005-2013 dan yang lain adalah kelompok reformis-pragmatis seperti Hashemi Rafsanjani (presiden 1989-1997), Muhammad Khatami (menjabat 1997-2005) dan Presiden Hassan Rouhani (2013-sekarang).

\section{Kritik dan Penentangan Terhadap Wilâyah Al-Faqîh}

Peran ulama dalam politik bukannya tanpa kritik, meskipun kekuasaannya sangat luas. Dalam praktiknya, beberapa inkonsistensi juga terjadi. Hal ini mungkin menunjukkan bahwa ideologi wilâyah al-faqîh sejak awal tidak diterima secara penuh oleh seluruh lapisan masyarakat Iran, atau minimal pelaksanaannya tidak sesuai harapan. Bahkan, mungkin juga disebabkan memang konsep wilâyah al-faqîh terlalu utopis untuk diterapkan di dunia politik modern yang menghendaki peran agama yang minimal.

Beberapa kritik dilancarkan oleh kalangan ulama, pemikir modernis Iran dan masyarakat Iran pada umumnya. Kritik oleh kalangan ulama mulai terdengar, khususnya sepeninggal Ayatullah Khomeini tahun 1989. Salah satu kritik disampaikan oleh Ayatullah Montazeri (w. 2009) yang merupakan salah satu murid dan pengikut setia Ayatullah Khomeini. Dialah penyusun

${ }^{24}$ Kenneth Katzman, Iran: Politics, Human Rights, and U.S. Policy, Congressional Research Service, 17 February, 2017, 2-8. 
utama Konstitusi Republik Islam Iran. Montazeri awalnya adalah kandidat kuat untuk menggantikan Khomeini, tetapi karena pandangannya yang berseberangan dengan Khomeini dalam beberapa isu, pada akhirnya posisinya direbut oleh Ali Khamenei yang lebih konservatif di tahun 1989.25

Montazeri menganggap penerapan wilâyah al-faq'h terlalu eksesif. Dia bahkan menganggap bahwa wilâyah al-faqih yang diterapkan saat itu lebih buruk daripada diktator komunis dan Syah Reza -pendiri kerajaan Pahlevi- karena ulama terlalu dalam ikut campur dalam permasalahan politik dan keberadaan polisi rahasia yang terlalu mengekang kehidupan sosial. Meskipun demikian, dia tetap mendukung sistem wilâyah al-faqih yang ada. Dia berpandangan bahwa seharusnya peran pemimpin tertinggi tidak pada urusan kenegaraan sehari-hari (day-to-day government) tetapi sebagai penjaga ideologi Islam Iran. Dia juga berpandangan bahwa lembaga pimpinan tertinggi ini seharusnya dilaksanakan dengan prinsip syûra, bukan pandangan pribadi. ${ }^{26}$ Dengan pandangannya itu, dia kemudian menunjukkan dukungannya pada reformis Muhammad Khatami menjelang pemilihan presiden tahun 1997. Dia sempat beberapa kali ditahan dan diancam untuk

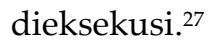

Selain Montazeri, suara miring juga disampaikan oleh Mohsen Saidzadeh, seorang mujtahid yang ditahan karena tidak setuju dengan rancangan perundangan yang melarang seorang dokter laki-laki memeriksa pasien perempuan. Dia juga banyak berkomentar yang mendukung wacana gender dalam Islam. Begitu juga dengan beberapa kasus lainnya. Bahkan, Hujjatul Islam Hasan Yusefi Eshkevari dihukum mati karena tuduhan telah menghina negara dan pemimpin negara, murtad dan memerangi Islam. Meskipun demikian, kasus-kasus yang melibatkan figur

\footnotetext{
${ }^{25}$ Alireza Nader, David E. Thaler, S. R. Bohandy, The Next Supreme Leader Succession in the Islamic Republic of Iran, (Santa Monica: RAND Corporation, 20 I I), 37-38.

${ }^{26}$ Ibid., 52.

${ }^{27}$ Charles Kurzman, "Critics Within: Islamic Scholars' Protests Against the Islamic State in Iran", International Journal of Politics, Culture and Society, I5:2, Winter 200 I, 346-348.
} 
dari kelompok ulama ini, tidak serta merta menggugat doktrin inti dari wilâyah al-faqih, melainkan pada pelaksanaannya.

Di pihak lain, kelompok Islam modernis seperti Ali Syari'ati berpandangan bahwa politik Islam harus dipisahkan dengan peran ulama di dalamnya. ${ }^{28}$ Selanjutnya, Mehdi Bazargan, mantan Perdana Menteri Iran, menyuarakan Islam modernis ini dengan beranggapan bahwa keterlibatan agama dalam politik cenderung akan mengikis wibawa agama. ${ }^{29}$ Hal senada juga disampaikan Abdul Karim Soroush yang beranggapan bahwa pembicaraan tentang Islam dan politik harus didekati dari luar agama. Mendamaikan demokrasi dan agama sama dengan mendamaikan antara akal dan wahyu. Masing-masing melibatkan nilai-nilai dan piranti di luar agama. Pada dasarnya, Soroush berpandangan bahwa karakter sebuah negara serta tata cara pemerintahan bukanlah urusan hukum agama, melainkan pembahasan filsafat politik. ${ }^{30}$

\section{Islam, Nasionalisme dan Identitas Persia}

Tidak lama setelah Revolusi Iran, Irak menyerang Iran. Ini menandai perang delapan tahun antara Irak dan Iran antara tahun 1980-1988. Dalam menggelorakan semangat perlawanan, pemimpin Iran, termasuk Khomeini, menggunakan sentimen yang tidak hanya berbasis Islam, melainkan nasionalisme. ${ }^{31}$ Demikian pula, sepeninggal Ayatullah Khomeini di tahun 1989, presiden Ali Akbar Hashemi Rafsanjani yang pragmatis mencoba mempersatukan Iran yang plural itu dengan menonjolkan nasionalisme, bukan Islam.

\footnotetext{
28 Sayangnya, Ali Syari'ati tidak berumur panjang untuk memperjuangkan pandangan politik Islamnya ini karena meninggal tahun 1975, empat tahun sebelum Revolusi Iran tahun 1979.

${ }^{29}$ Said Amir Arjomand, "The State(s) of Ideology in Iran", Policy Watch 2576, 29 February, 2016.

30 Forough Jahanbakhsh, "Abdol Karim Soroush: New Revival of Religious Sciences", ISIM Newsletter, 8/0I, 21.

${ }^{31}$ Rasmus Christian Elling, "Matters of Authenticity: Nationalism, Islam, and Ethnic Diversity in Iran", dalam Negin Nabavi (ed), Iran: From Theoracy to Green Movement, (New York: Palgrave McMillan, 20I2), 81.
} 
Selain multi etnis, Iran juga masih terbelah antara pro status quo dan loyalis Reza Pahlevi yang mayoritas adalah kelompok elit sekuler modern. Masa kepresidenan Muhammad Khatami yang dikenal reformis-pragmatis juga mengembangkan nasionalisme ini di samping civil society, aktifitas oposisi dan kehidupan budaya dan seni. Paling tidak, ada dua jenis nasionalisme yang muncul; yaitu nasionalisme berbasis agama (melli-mazhabi) dan nasionalisme sekuler (melli-gara). ${ }^{32}$ Bahkan, presiden Ahmadinejad yang dikenal konservatif pun tidak luput dari upaya menggalang nasionalisme Iran dengan melakukan proyeksi jauh ke belakang; yaitu kejayaan Persia. Pada periode kedua masa jabatannya sebagai presiden (2009-2013), Ahmadinejad berkolaborasi dengan kelompok sekuler yang menggunakan identitas Iran pra-Islam sebagai identitas dalam upayanya menggalang dukungan dari kalangan kelas menengah sekuler yang terlihat mulai putus asa dengan kondisi Iran saat itu. ${ }^{33}$ Keputusan ini pun menyebabkan kecaman keras dari kelompok ulama konservatif karena pemerintahannya sudah dianggap melenceng dari kehendak pemimpin tertinggi. ${ }^{34}$ Akan tetapi, hal ini tidak menghalangi Ahmadinejad menerima gelar sebagai 'Cyrus Masa Kini'. ${ }^{35}$

Lunturnya ideologi Islam ini terjadi pada sebagian kalangan generasi tua yang merasa menyesal telah mendukung Revolusi tahun 1979 dan khususnya terjadi pada generasi baru di Iran yang tidak menyaksikan atau terlibat dalam revolusi Iran tahun 1979. Terkait generasi muda ini, menurut penelitian Abdolmohammadi, lebih dari $50 \%$ penduduk Iran saat ini berusia 40 tahun ke bawah. ${ }^{36}$ Merekalah sumber pendulang suara Muhammad Khatami ketika memenangi pemilihan presiden di tahun 1997. Nasionalisme Iran

\footnotetext{
32 Ibid., 82.

33 Ibid., 84.

${ }^{34}$ Ibid., 82.

${ }^{35}$ Cyrus atau Koresh (600-530 SM) adalah raja Persia kuno yang dikenal adil yang berhasil mempersatukan Persia di bawah satu kekuasaan politik dengan menaklukkan Babilonia, Media dan Lydia.

36 Pejman Abdolmohammadi, "The Revival of Nationalism and Secularism in Modern Iran", dalam LSE Middle East Centre Paper, Series I I, November 20 I 5, 7.
} 
ini lagi-lagi menggali akar Persia pra-Islam. Mereka mulai mengagung-agungkan pahlawan Persia seperti Cyrus, Dariush, dan Rostam. Nama-nama Persia ini juga mulai banyak digunakan untuk bayi yang lahir menggantikan nama-nama Islami seperti Mehdi, Mohammad, Ali dan Hossein. Kosa kata Persia juga mulai banyak digunakan untuk menggantikan kosa kata yang berasal dari Bahasa Arab, misalnya 'Dorud' yang menggantikan 'Salam'. Pengagungan Persia juga merambah di dunia sastra dan musik. Ziarah ke situs-situs bersejarah pra-Islam, seperti kota tua Persepolis dan Pasargad, juga semakin marak. Siaran televisi dan website internet yang menayangkan kejayaan Persia juga menduduki rating yang tinggi. ${ }^{37}$

Selain ekspresi budaya pop, Abdolmohammadi juga melaporkan banyaknya fenomena atheisme dan perpindahan agama dari Islam ke agama lain, khususnya Zoroastrian (Majusi), Baha'i, Kristen dan bahkan Buddhisme di kalangan generasi muda. Bahkan, sebuah survei di tahun 2015 yang diadakan di kalangan remaja diaspora Iran di Eropa, hanya 35\% yang mengaku muslim, itu pun hanya nominal. ${ }^{38}$ Begitu pula kedatangan Muslim ke masjid (mosque attendance) di Iran tercatat terendah di antara beberapa negara-negara berpenduduk muslim besar di dunia. Selain hal itu, politisasi agama juga dianggap berpengaruh besar terhadap rendahnya kehadiran ke masjid. Pemahaman agama yang sangat dimonopoli dan kehidupan sosial dan budaya yang selalu diawasi oleh negara berbuah keengganan masyarakat untuk menghadiri masjid. ${ }^{39}$ Selain itu, ritual pernikahan ala Persia juga mulai marak kembali. Perayaan hari-hari besar Persia, seperti Tahun Baru Persia dan Perayaan Api, juga semakin marak dilakukan. ${ }^{40}$

${ }^{37}$ Ibid., 9.

38 lbid.

39 Ibid., 10.

40 Ibid., I I. 
Aura nasionalisme yang berbasis identitas Persia dan sekularisme ini mengemuka di tahun 2009 menyusul demonstrasi atas dugaan kecurangan pemilihan presiden. Dalam pemilihan ini, Maohmoud Ahmadinejad dianggap telah banyak dibantu secara tidak adil oleh kalangan konservatif yang menguasai pemerintahan untuk memenangi pemilihan mengalahkan kandidat reformis, Mir-Hossein Mousavi. ${ }^{41}$ Gerakan yang dikenal dengan Green Movement (gerakan hijau) ini dimotori oleh para pemuda yang berasal dari generasi Iran pasca Revolusi.

Secara ideologis, gerakan hijau ini berasal dari dua kelompok besar, yaitu kelompok sekuler yang memperjuangkan berdirinya demokrasi yang sekuler di Iran, dan kelompok aktifis demokrasi Islam yang mengidamkan demokrasi Islam yang lebih substansial tanpa campur tangan ulama. Dua kelompok ini memiliki kesamaan tuntutan, yaitu: pendirian sebuah negara demokratis yang menjunjung tinggi supremasi hukum, pemisahan agama dengan politik, kebebasan berpendapat dan perlindungan seluruh kelompok minoritas.42 Slogan-slogan yang diusung, khususnya oleh kelompok sekuler, pada saat demonstrasi antara lain: 'kemerdekaan, kebebasan dan republik Iran' dan pernyataan ras Arya serta pemisahan agama dan politik.

Republik Iran yang dimaksud haruslah berakar pada identitas Persia, bukan Arab-Islam.43 Gerakan hijau yang memang sejak awal tidak didesain ataupun terorganisir ini akhirnya berhasil diredam oleh otoritas Iran dengan langkah represif tanpa kompromi. ${ }^{44}$ Meskipun demonstrasi mereka dipatahkan oleh rezim yang berkuasa, sebagai sebuah gerakan yang sifatnya tidak terstruktur, ideologi nasionalisme sekuler yang berbasis budaya populer ini nampaknya terus berkembang di masyarakat. Dalam

\footnotetext{
${ }^{4}$ Victor H. Sundquist, "Iranian Democratization Part I: A Historical Case Study of the Iranian Green Movement", Journal of Strategic Security, 6, No. I (2013), 19.

${ }^{42}$ Pejman Abdolmohammadi, "The Revival of Nationalism and Secularism in Modern Iran", I4.

43 lbid., 15.

${ }^{44}$ Victor H. Sundquist, "Iranian Democratization Part I: A Historical Case Study of the Iranian...", 20.
} 
aspek politik, aspirasi kelompok sekuler nasionalis ini seringkali disalurkan melalui kandidat presiden reformis. Hal itu dibuktikan dengan kemenangan mutlak kandidat reformis Hassan Rouhani pada pemilihan presiden tahun 2013 yang menurut beberapa analisis, kelompok kelas menengah sekuler nasionalis menyumbang suara yang signifikan. ${ }^{45}$

\section{Real Politics vis-a-vis Ideologi dalam Perpolitikan Iran}

Sejalan dengan munculnya kelompok reformis yang cenderung pragmatis di Iran yang terepresentasi dalam lembaga kepresidenan, kebijakan pemerintah Iran menjadi tidak selalu berbasis ideologis semata, melainkan juga pragmatis. Kelompok ini cenderung lebih lunak terhadap Barat dalam politik luar negeri, terbuka pada investasi asing di bidang ekonomi, dan terbuka pada budaya luar. Di pihak lain, ulama konservatif masih bersikukuh dalam menerapkan ideologi Islam dalam seluruh bidang kehidupan, baik area privat ataupun publik. Kelompok konservatif menampakkan sikap yang keras terhadap Barat, curiga terhadap modal asing, dan bersikap chauvinistic dan protektif terhadap budaya Islam Iran. ${ }^{46}$

Dalam perebutan kekuasaan dan pengaruh, dua kelompok ini selalu terlibat. Jika dihitung, maka presiden yang memiliki kecenderungan reformis-pragmatis ini lebih banyak dipilih oleh rakyat dibanding dengan presiden konservatif. Presiden yang memiliki pandangan konservatif adalah Ali Khamenei (yang sekarang menjadi Pemimpin Tertinggi) yang menjabat selama delapan tahun (1981-1989) di kala Ayatullah Khomeini masih hidup dan Mahmoud Ahmadinejad selama delapan tahun (20052013). Sedangkan dari kalangan reformis-pragmatis adalah Ali Akbar Hashemi Rafsanjani selama delapan tahun (1989-1997), Muhammad Khatami selama delapan tahun (1997-2005) dan Hassan Rouhani (2013-sekarang). Pada 19 Mei 2017, dilaksanakan

${ }^{45}$ Pejman Abdolmohammadi, "The Revival of Nationalism and Secularism in Modern Iran", 18.

${ }^{46}$ Smith Alhadar, "Dua Aliansi dalam Pemilihan Presiden Iran", Koran Tempo, 18 Mei 2017. 
pemilihan presiden lagi. Presiden petahana, yaitu Hassan Rouhani kembali mencalonkan diri dan ditantang oleh calon konservatif, Ebrahim Raisi yang didukung penuh oleh Pemimpin Tertinggi dan Korps Tentara Revolusi. Lagi-lagi, petahana menang dan melanjutkan politik reformis-pragmatis untuk empat tahun ke depan. ${ }^{47}$

Kecenderungan untuk memilih presiden yang memiliki latar belakang reformis-pragmatis menunjukkan bahwa berpegang teguh pada ideologi semata tidaklah sejalan dengan aspirasi masyarakat Iran. Terdapat beberapa sebab yang mungkin menjadi alasannya. Yang pertama adalah karena ketidaknyamanan beberapa elemen masyarakat Iran dengan ideologi Islam yang dianut oleh negara atau minimal pelaksanaannya. Hal ini sudah tercermin dalam beberapa kritik yang muncul terhadap ideologi tersebut dan perkembangan sosial budaya yang disampaikan sebelumnya. Yang kedua adalah karena sebagaimana politik di lain konteks, terdapat kesulitan besar dalam menerapkan ideologi secara konsisten dalam politik. Contohnya, Presiden Mahmoud Ahmadinejad sejatinya adalah nasionalis konservatif dan memegang teguh ideologi Revolusi Islam. Akan tetapi, kepemimpinan ideologis dan agresif Ahmadinejad ini malah mendatangkan kerugian bagi Iran sebagai sebuah negara. Pengembangan nuklir yang semakin intensif dan sikap konfrontatif terhadap Barat dan kepentingannya berbuah keterpurukan ekonomi yang semakin menjerumuskan Iran menjadi negara pariah dalam masa pemerintahannya. ${ }^{48}$

Oleh karena itu, fleksibilitas dalam melaksanakan ideologi negara kadang diperlukan demi target yang lebih besar. Contoh yang paling gamblang adalah komunisme China saat ini yang mengompromikan antara komunisme dan kapitalisme pasar.

\footnotetext{
${ }^{47}$ Allazeera.com, "Hassan Rouhani Wins Iran's Presidential Election", dalam http://www.aljazeera.com/news/20 I7/05/iran-election-president-hassan-rouhani-takes-leadI70520042625946.html, diakses pada 2I Mei 2017.

${ }^{48}$ Abdul Qader Fayez, "The Iranian Presidential Elections: Internal Challenges, Critical Issues", AlJazeere Center for Studies, dalam http://studies.aljazeera.net/en/, 24 Maret 20I3, 3.
} 
Demikian pula bagi kelompok reformis-pragmatis Iran, desakan akan kebutuhan pragmatis seperti kebutuhan dasar ekonomi mengharuskan melakukan kompromi-kompromi beberapa aspek tertentu dari ideologi Islam Iran. Di masa lalu, Presiden Muhammad Khatami dianggap representasi dari kelompok reformis dan pragmatis dalam menentukan keputusan politik. Dia cukup berhasil dalam mengembangkan civil society dan gerakan oposisi di Iran meski dengan pembatasan kekuasaan yang begitu ketat oleh Ali Khamenei sebagai Pemimpin Tertinggi yang konservatif. Menurut Said Amir Arjomand, salah satu aspek penting ideologi Islam Iran yang ditinggalkan adalah aspirasi untuk mengekspor revolusi Islam ke wilayah Islam lainnya menyusul gagalnya upaya tersebut di Irak, Bahrain, Afghanistan dan Pakistan. Bahkan dalam kasus Pakistan, kegagalan ini berbuntut panjang dengan berlangsungnya konflik sectarian yang berkepanjangan. Pada akhirnya, upaya ini hanya berhasil dicangkokkan ke Lebanon dengan kuatnya milisi Hezbollah di negara tersebut. ${ }^{49}$

Salah satu wujud kebijakan pragmatisme ini adalah keputusan Presiden Hassan Rouhani untuk mempercepat negosiasi nuklir Iran dengan negara P5+1 (Amerika Serikat, Inggris, Prancis, Rusia, China dan Jerman) yang berakhir dengan ditandatanganinya JCPOA (Joint Comprehensive Plan of Action) tahun 2015.50 Keputusan untuk menuntaskan negosiasi nuklir ini mengakhiri upaya diplomatis yang telah dirintis sejak awal tahun 2002 antara Iran dan Barat. Diplomasi ini sebelumnya dibangun atas kepentingan bersama melawan terorisme menyusul peristiwa teror 9/11 dan kemunculan al-Qaeda. Upaya ini tidak berjalan mulus karena terkuaknya upaya Iran dalam mengembangkan nuklir ditambah dengan kepemimpinan Mahmoud Ahmadinejad

\footnotetext{
${ }^{49}$ Said Amir Arjomand, "The State(s) of Ideology in Iran", Policy Watch 2576, 29 February, 2016

${ }^{50}$ Negosiasi dengan Barat sebenarnya sudah lama dirintis akan tetapi selalu menemui jalan buntu, khususnya di masa kepresidenan Ahmadinejad yang konservatif dan diketahuinya Iran mengembangkan nuklir.
} 
yang konservatif dan cenderung konfrontatif dengan Barat. Hal ini berujung sanksi ekonomi atas Iran tahun 2006.

Meskipun negosiasi terus dilakukan di masa kepresidenan Ahmadinejad, momentum dan optimisme muncul setelah Hassan Rouhani yang dianggap reformis terpilih menjadi Presiden tahun 2013. Upaya Hassan Rouhani melanjutkan negosiasi secara sungguh-sungguh ini dianggap pragmatis karena harus melakukan kompromi-kompromi politik dengan negara-negara yang selama ini secara tradisional dianggap musuh Iran, khususnya Amerika Serikat. Perjanjian ini adalah sebuah kesuksesan diplomatik yang besar dan merupakan solusi jangka panjang bagi nulir Iran sekaligus sebagai dasar kerjasama Iran dengan masyarakat dunia.

Dari aspek ekonomi, perjanjian nuklir ini menjanjikan prospek yang cerah, khususnya terkait dengan pemasaran minyak Iran, pencairan harta Iran hasil penjualan minyak yang dibekukan senilai kira-kira 100 Milyar Dollar, dan dalam jangka panjang perbaikan ekonomi Iran yang telah terpuruk dalam beberapa dasawarsa terakhir karena sikap konfrontatif dengan kekuatan besar dunia. ${ }^{51}$ Secara eksplisit, JCPOA yang ditandatangani pada tanggal 14 Juli 2015 dan berlaku selama 10 tahun ini menghalangi segala cara yang memungkinkan Iran untuk memperoleh bahanbahan yang dibutuhkan untuk membuat senjata nuklir. Iran harus mengurangi dua pertiga jumlah sentrifugal yang dimiliki, merubah fasilitas nuklir di daerah Fardow menjadi fasilitas nuklir sipil, mengubah reaktor di Arak dan membuang bahan bakar reaktornya, serta membuang cadangan uranium yang dimiliki. Iran juga harus memperkenankan IAEA (International Atomic Energy Agency) untuk melakukan pengawasan yang diperlukan

51 Paolo Magri, "Introduction", dalam Paolo Magri dan Annalisa Perteghella (ed), Iran after the Deal: the Road Ahead, (Roma: ISPI, 20 I6), 7. 
untuk memastikan bahan yang dimiliki Iran tidak dijadikan bom secara rahasia. ${ }^{52}$

Di dalam negeri, secara umum semua elemen masyarakat menyetujui JCPOA ini, meskipun berbeda pandangan dalam rinciannya. Sebagian besar masyarakat Iran menanggapinya dengan suka cita dan mendaulat Javad Zarif, menteri luar negeri Iran yang mewakili Iran dalam negosiasi tersebut, sebagai "Mosaddeq" baru. ${ }^{53}$ Sebagian yang lain, termasuk pimpinan tertinggi Iran, menanggapinya dengan kehati-hatian dan tetap mencurigai motif-motif terselubung Barat di balik perjanjian ini, meskipun Ali Khamenei sebenarnya memiliki keberatan teologis mengenai senjata nuklir. ${ }^{54}$ Sedangkan kelompok konservatif lainnya berpandangan bahwa dalam perjanjian ini Iran terlalu banyak memberikan konsesi dengan imbalan yang tidak seberapa. ${ }^{55}$

Perlu diketahui, bahwa beberapa sanksi Barat lainnya masih belum dicabut, khususnya sanksi unilateral Amerika Serikat karena Iran dianggap masih mendukung kelompok-kelompok teroris dan berkontribusi besar terhadap instabilitas di Timur Tengah. ${ }^{56}$ Perbedaan pandangan terkait dengan JCPOA ini menggambarkan perbedaan yang cukup tegas di antara kelompok reformis dan kelompok reformis-pragmatis dalam melaksanakan ideologi politik di Iran.

\section{Penutup}

Ideologi Islam di Iran diwujudkan dengan pemerintahan Islam yang dilaksanakan oleh para ulama melalui prinsip wilâyah al-faq h̆. Kekuasaan ini merupakan kelanjutan dari kewenangan para imam Syi'ah. Berdirinya Republik Islam Iran sejak tahun 1979

\footnotetext{
52 Aniseh Bassiri Tabrizi, "The Nuclear Deal: Exploiting Its Potential", dalam Paolo Magri dan Annalisa Perteghella (ed), Iran after the Deal: the Road Ahead, (Roma: ISPI, 20 I6), 17- I8.

${ }^{53}$ Shervin Malekzadeh,"'Where Iran's Hard-Liners Diverge From The Moderates", Iran and the Nuclear Deal, POMEPS Studies, 13, 29 April 20 I5, 5.

${ }^{54}$ James S. Ribbon, "Iranian Ideology after the Nuclear Deal"..., 3.

55 Ibid.

${ }^{56}$ Aniseh Bassiri Tabrizi, "The Nuclear Deal: Exploiting Its Potential"..., I8.
} 
telah berupaya melaksanakan ajaran Islam dalam ranah privat dan publik menurut pemahaman yang diyakini para ulama. Posisiposis politik dibentuk untuk memastikan kekuasaan ulama dimana para ulama menjadi penentu pamungkas segala urusan keagamaan dan juga politik.

Dalam pelaksanaannya, ideologi ini tidaklah mudah diterapkan. Mulai bermunculan kritik dan penentangan, baik yang mempersoalkan kewenangan ulama atau bahkan keberadaan Republik Iran. Sebagian ulama bersikap kritis terhadap penerapan wilâyah al-faq hh, meskipun tetap mendukungnya. Sebagian generasi muda Iran bahkan sudah apatis atau bahkan menentang pemerintahan Islam di Iran. Di lain pihak, di dalam rezim ulama yang berkuasa juga mulai muncul pergeseran dalam menerapkan ideologi Islam. Kemunculan kelompok reformis-pragmatis di samping kelompok konservatif menunjukkan hal ini.

Pragmatisme dalam politik Iran sudah terekam sejak lama, terutama di masa pemerintahan presiden yang reformispragmatis, contohnya seputar pemilihan presiden dan keputusan Iran dalam menegosiasikan proyek nuklirnya untuk memperoleh penghapusan sanksi ekonomi yang telah menghimpit cukup lama. Kecenderungan-kecenderungan terakhir ini menunjukkan bahwa ideologi Islam yang dilaksanakan oleh para ulama sudah mengalami banyak pergeseran sehingga sulit mencari otentisitas ideologi ini.

\section{Daftar Pustaka}

Abdolmohammadi, Pejman. "The Revival of Nationalism and Secularism in Modern Iran", dalam LSE Middle East Centre Paper, Series 11, November 2015.

Alhadar, Smith. "Dua Aliansi dalam Pemilihan Presiden Iran", Koran Tempo, 18 Mei 2017.

AlJazeera.com, "Hassan Rouhani Wins Iran's Presidential

Election", dalam http://www.aljazeera.com/news/2017/05/ 
iran-election-president-hassan-rouhani-takes-lead170520042625946.html, diakses pada 21 Mei 2017.

Amanat, Abbas. "From Ijtihad to Wilayat-i Faqih: The Evolving of the Shi'i Legal Authority into Political Power", dalam Abbas Amanat (ed). Apocaliptic Islam and Iranian Shi'ism. New York: IB Tauris, 2009.

Arjomand, Said Amir. "Introduction: Shiism, Authority and Political Culture", dalam Said Amir Arjomand (ed). Authority and Political Culture in Shi'ism. New York: SUNY Press, 1988.

------. "The State(s) of Ideology in Iran", Policy Watch 2576, February 29, 2016.

Banuazizi, Ali. Islamic State and Civil Society in Iran. Invited Joseph Sterlitz Annual Lecture in Middle Eastern Studies. Tel Aviv University, April 18, 1999.

Constituteproject.org, "Iran (Islamic Republic of)'s Constitution of 1979 with Amendments through 1989", dalam https://www.constituteproject.org/constitution/Iran_1989.pd f?lang=en, diakses pada 10 Mei 2017.

Fayez, Abdul Qader. "The Iranian Presidential Elections: Internal Challenges, Critical Issues, AL-Jazeere Center for Studies", dalam http://studies.aljazeera.net/en/, diakses pada 24 Maret 2013.

Elling, Rasmus Christian. "Matters of Authenticity: Nationalism, Islam, and Ethnic Diversity in Iran", dalam Negin Nabavi (ed). Iran: From Theoracy to Green Movement. New York: Palgrave McMillan, 2012.

Jahanbakhsh, Forough. "Abdol karim Soroush: New Revival of Religious Sciences", ISIM Newsletter, 8/01.

Katzman, Kenneth. Iran: Politics, Human Rights, and U.S. Policy. Congressional Research Service, February 17, 2017.

Kohlberg, Etan. "Imam and Community in the Pre-Ghayba Period", dalam Said Amir Arjomand (ed). Authority and Political Culture in Shi'ism. New York: SUNY Press, 1988. 
Kurzman, Charles. "Critics Within: Islamic scholars' protests against the Islamic State in Iran", International Journal of Politics, Culture and Society, 15:2, Winter 2001.

Magri, Paolo. "Introduction", dalam Paolo Magri dan Annalisa Perteghella (ed). Iran after the Deal: the Road Ahead. Roma: ISPI, 2016.

Malekzadeh, Shervin. "Where Iran's Hard-Liners Diverge From The Moderates". Iran and the Nuclear Deal, POMEPS Studies, 13, 29 April 2015.

Momen, Moojan. An Introduction to Shi'I Islam: The history and doctrine of Twelve Shi'ism. New Haven: Yale University Press, 1985.

Mussavi, Hamad Kazemi. "Usuliyya", dalam Richard C. Martin (ed). Encyclopedia of Islam and the Muslim World. New York: McMillan Reference USA, 2004.

Nader, Alireza, David E. Thaler, S. R. Bohandy. The Next Supreme Leader Succession in the Islamic Republic of Iran. Santa Monica: RAND Corporation, 2011.

Ribbon, James S. "Iranian Ideology after the Nuclear Deal". Iran Strategy Brief, The American Foreign Policy Council, 8, Januari 2017.

Sundquist, Victor H. "Iranian Democratization Part I: A Historical Case Study of the Iranian Green Movement". Journal of Strategic Security, 6, No. 1, 2013.

Tabrizi, Aniseh Bassiri. "The Nuclear Deal: Exploiting Its Potential", dalam Paolo Magri dan Annalisa Perteghella (ed). Iran after the Deal: the Road Ahead. Roma: ISPI, 2016. 